Determination of Platinum, Iridium, and Rhodium in Uranium Alloys by Atomic-Absorption Spectrophotometry 
This repori was prepared as an acccunt of work sponsored by the United States Government. Neither the United States nor the United States Atomic Energy Commission, nor any of their employees, nor any of their contractors, subcontractors, or their employees, makes any warranty, express or implied, or assumes any legai liability or responsibility for the accuracy, completeness or usefuiness of any information, apparatus, product or process disclosed, or represents that its use would not infringe privately owned rights.

Printed in the United States of America. Available from

National Technical Information Service

U. S. Department of Commerce

5285 Port Royal Road

Springfield, Virginia 22151

Price: Printed Copy $\$ 4.00$; Microfiche $\$ 0.95$ 


\title{
Determination of Platinum, Iridium,
} and Rhodium in Uranium Alloys by

\section{Atomic-Absorption Spectrophotometry}

by

\author{
R. D. Gardner
}

A. L. Henicksman

W. H. Ashley

\footnotetext{
This report was prepared as an account of work sponsored by the United States Government. Neither the United States nor the United Stotes Atomic Enerzy Commisston, nor eny of their employees, nor any of their coniractors, subcontrictors, or thefr employees, makes any warranty, express or implied, or assumes any legal liability or responsibility for the accuracy com pleteness or usefulness of any information, pleteness or userul disclosed, or represents, product or process disclosed, or represents that its ute would not infringe privately owned rights.
} 


\title{
DETERMINATION OF PLATINUM, IRIDIUM, AND RHODIUM IN URANIUM ALLOYS BY ATOMIC-ABSORPTION SPECTROPHOTOMETRY
}

by

R. D. Gardner, A. L. Henicksman, and W. H. Ashley

\begin{abstract}
Platinum, iridium, and rhodium, at concentrations of 0.01 to $1 \mathrm{wt} \%$ in uranium-matrix alloys, are measured by a rapid atomic-absorption spectrophotometric method. The alloys are dissolved in hydrochloric and nitric acids (in a sealed tube if iridium is involved), and the noble metals are measured in this solution without separation. The uranium effectively suppresses interelement atomic-absorption effects and at the same time enhances the sensitivfies of the individual noble metals. The measurement relative standard deviation generally is no greater than $1 \%$ in analyzing alloys zontaining 0.1 to 1 wt\% of noble metals, and no greater than $7 \%$ at the $0.01-w$ :\% alloy level.
\end{abstract}

\section{INTRODUCTION}

Early in the development of the atomic-absorption technique, it was recognized that it should be well-suited to determination of the platinum metals. ${ }^{\prime}$ Since then, numerous interferences have been observed, including the interelement effects of the noble elements themselves. A frequently proposed way to eliminate these interferences is to add uranium. Scarborough, ${ }^{2}$ working with uranium fissium, found that uranium completely eliminated the interelement effects of molybdenum, ruthenium, rhodium, and palladium. Montford and Cribbs ${ }^{3}$ confirmed these findings for ruthenium, and Mallet et al. ${ }^{4}$ found that adding uranium very effectively prevented mutual interferences in solutions containing palladium, rhodium, ruthenium, platinum, and gold. Our own interests were in uranium alloys containing 0.01 to $1 \mathrm{wt} \%$ each of platinum, iridium, and rhodium. The aim of this study was to establish suitable analysis conditions and to determine the precision that could be expected.

\section{RECOMMENDED PROCEDURE}

A. Special Apparatus

Atomic-Absorption Spectrophotometer, Varian Techtron AA-4, with IM-5 amplifier module and DI-30 digital indicator.

Electric Oven, operable at $300^{\circ} \mathrm{C}$.

Hand Torch, for oxygen and natural gas.

Lamps, Hollow-catbode, for platinum, iridium. and rhodium, HCN series from Varian Techtron.

Tubes, heavy-wall fused-silica or Pyrex, approximately 8-mm bore, 2-mm wall thickness, $38 \mathrm{~cm}$ long, with one end sealed. 


\section{B. Reagents}

Carbon Dioxide, dry ice, finely chopped.

Hydrocbloric Acid, 12N, reagent grade.

Metal Solutions, approximately $1 \mathrm{mg} / \mathrm{ml}$. Individual solutions of platinum, iridium, and rhodium were prepared by dissolving accurately weighed, approximately $100 \mathrm{mg}$ samples of earh pure metal separately and diluting to $100 \mathrm{ml}$. The sealed-tube method of Wichers et al. ${ }^{5}$ was used to dissolve the metals.

Nitric Acid, 15N, reagent grade.

Uranium solution, $200 \mathrm{mg} / \mathrm{ml}$. Pure uranium metal was dissolved in hydrochloric acid, $U(I I I)$ and $U(I V)$ were oxidized with hydrogen peroxide, and the solution was diluted to appropriate volume.

\section{Sample Preparation}

The alloy samples are ordinarily received in the form of turnings, and the portions taken for analysis should be carefully inspected to ensure the absence of foreign material that may have been introduced in machining or sampling. If cutting oil is present, the sample should be washed sequentially with water, ethanol, and acetone, and then allowed to dry at room temperature. The recommended 1-g sample size and $25-\mathrm{ml}$ final solution volume are usable for all three metals in the 0.01- to 1.0-wt\% range, but for rhodium at $1 \mathrm{wt} \%$ a more dilute solution is preferred. At the 0.01-wt\% level, scale expansion will be needed, especially for iridium, but a more concentrated sample solution is not recommended.

\section{Operations}

1. If the alloy is known not to contain iridium, place a weighed $1 \mathrm{~g}$ sample in a $100-\mathrm{ml}$ beaker and add $12 \mathrm{M}$ hydrochloric acid cautiously, as the uranium reacts, to a final volume of $3 \mathrm{ml}$. When the reaction subsides, add enough nitric acid to oxidize the uranium, dilute to volume in a $25-\mathrm{ml}$ volumetric slask, and proceed with Step 5.

2. If the sample contains iridium, place a weighed $1-g$ sample in a heavy-walled fused-silica or Pyrex tube and add $6 \mathrm{ml}$ of $12 \mathrm{M}$ hydrochloric acid, dropwise at first.

3. Place the tube in dry ice to freeze the solution, add 4 drops of $15 \mathrm{M}$ nitric acid, and seal the tube, using a hand torch, less than 12 in. from the closed end. Proceed with the dissolution as described by Wichers ${ }^{5}$ or by Metz and Waterbury. ${ }^{6}$

4. After opening the tube, wash the contents into a $100-\mathrm{ml}$ beaker, heat a few minures to remove excess chlorine, and then cool and make to volume in a $25-\mathrm{ml}$ flask.

5. Prepare two calibration solutions containing the same concentrations of uranium and hydrochloric acid as the sample solution. To one of these solutions, add a volume of the metal solution of the element being sought to give the same concentration as expected in the sample. Use the second solution as the blank.

6. Use the appropriate hollow-cathode lamp and the instrument setrings shown in Table $I$, and adjust the instrument sensitivity as necessary.

7. Aspirate the blank, the calibration solution, the sample solutions in order, the calibration solution, and the blank, recording the absorbances. After verifying the base line with water, repeat the sequence in reverse. Repeat the measurements until results agre-ing within established limits of precision (see Table IV) are obtained. Average the readings for each solution and subtract the absorbance of the blank from each sample reading.

8. Calculate the concentration of the element in the sample.

$$
\text { Element sought, wt\% }=\frac{A \times B \times 100}{C \times D}
$$

where

$$
\begin{aligned}
& \mathbf{A}=\text { grams of element in calibration solution, } \\
& \mathbf{B}=\text { net absorbance of sample solution, } \\
& \mathbf{C}=\text { net absorbance of calibration solution, } \\
& \mathbf{D}=\text { grams of sample taken. }
\end{aligned}
$$

\begin{tabular}{|c|c|c|c|c|c|c|}
\hline Element & $\begin{array}{l}\text { Wave- } \\
\text { length } \\
\text { (A) }\end{array}$ & $\begin{array}{l}\text { Lamp } \\
\text { Current } \\
\text { (mA) }\end{array}$ & $\begin{array}{l}\text { Slit } \\
(\mu)\end{array}$ & $\begin{array}{l}\text { Burner } \\
\text { Height } \\
\text { (mm) }\end{array}$ & $\begin{array}{l}\text { Acetylene } \\
\text { Flow }\end{array}$ & $\underset{\text { (psig) }}{\text { Air }}$ \\
\hline $\begin{array}{l}\mathbf{P t} \\
\mathbf{I r} \\
\mathbf{R h}\end{array}$ & $\begin{array}{l}2659 \\
2640 \\
3435\end{array}$ & $\begin{array}{l}10 \\
20 \\
10\end{array}$ & $\begin{array}{l}25 \\
25 \\
50\end{array}$ & $\begin{array}{l}5 \\
8 \\
6\end{array}$ & $\begin{array}{l}4 \\
5 \\
3.5\end{array}$ & $\begin{array}{l}20 \\
20 \\
20\end{array}$ \\
\hline
\end{tabular}

TABLE I

\section{RECOMMENDED TECHTRON AA-4 INSTRUMENT SETTINGS}




\section{I. EXPERIMENTAL}

\section{A. Anion Effects}

As the absorbance of a dissolved metal may be greater in one acid than in another, we measured the relative absorbances of platinum, iridium, and rhodium in various acids at the wavelengths given in Table 1 . Aliquots of each metal solution were evaporated to near dryness to remove hydrochloric acid, and the residues were dissolved in $10 \%$ solutions of the various acids. We prepared two solutions in each acid, and to one of each pair added uranium to the extent of $40 \mathrm{mg} / \mathrm{ml}$. The solutions were anlyzed as described in Steps 4 through 8 above, with the results shown in Table II. In each case, platinum concentration was $400 \mathrm{ppm}$, iridium $250 \mathrm{ppm}$, and rhodium $100 \mathrm{ppm}$. The instrument sensitivity was not kept constant, and the absorbances do not indicate the relative sensitivities for the three elements. Note that the differences due to the acids are relativily less when uranium is present, and in only one case (iridium without uraniun) is any other acid superior to hydrochloric. This is fortunate because hydrochloric acid is the most convenient solvent. The data also show that the presence of uranium gives considerable enhancement in all but one case (platinum in sulfuric acid).

\section{B. Carion Effects}

We studied only the effects of the three elements on each other. We prepared sample solutions containing pairs of the three noble elements in approximately equal concentrations and analyzed these solutions using in the calibration solutions the single element being sought. We then repeated the process after adding uranium to both the sample and calibration solutions. Table III shows the

TABLE II

EFFECTS OF YARIOUS ACIDS ON ABSORBANCE

\begin{tabular}{|c|c|c|c|c|c|c|}
\hline \multirow{3}{*}{$\begin{array}{l}\text { Asid } \\
\text { Used, } \\
10 \% \\
\end{array}$} & \multicolumn{6}{|c|}{ Absorbance } \\
\hline & \multicolumn{2}{|c|}{$\begin{array}{l}\text { Platinum } \\
\text { (2659 A) }\end{array}$} & \multicolumn{2}{|c|}{$\begin{array}{c}\text { Iridium } \\
(2640 \mathrm{~A})\end{array}$} & \multicolumn{2}{|c|}{$\begin{array}{l}\text { Rhodium } \\
\text { (3435 A) }\end{array}$} \\
\hline & No U & $\begin{array}{c}U^{x} \\
\text { Added }\end{array}$ & No U & $\begin{array}{c}\mathbf{U}^{\mathbf{2}} \\
\text { Added }\end{array}$ & No $U$ & $\begin{array}{c}U^{2} \\
\text { Added }\end{array}$ \\
\hline $\mathrm{HCl}$ & 0.306 & 0.388 & 0.046 & 0.410 & 0.252 & 0.438 \\
\hline HNO, & 0.306 & 0.386 & 0.140 & 0.352 & 0.239 & 0.444 \\
\hline $\mathrm{H}_{2} \mathrm{SO}_{4}$ & 0.249 & 0.171 & 0.030 & 0.118 & 0.147 & 0.257 \\
\hline $\mathrm{HClO}_{4}$ & 0.053 & 0.317 & 0.093 & 0.310 & 0.247 & 0.368 \\
\hline $\mathrm{H}_{3} \mathrm{PO}_{4}$ & 0.247 & 0.314 & 0.034 & 0.338 & 0.074 & 0.301 \\
\hline
\end{tabular}

$240 \mathrm{mg} \mathrm{U} / \mathrm{ml}$.
TABLE III

\section{MUTUAL INTERFERENCES WITH AND WITHOUT URANIUM}

\begin{tabular}{|c|c|c|c|}
\hline \multirow[b]{3}{*}{ Taken (mg) } & \multirow{3}{*}{$\begin{array}{c}\text { Interferent } \\
\text { Added (mg) }\end{array}$} & \multicolumn{2}{|c|}{ Found ( $\%$ of taken) } \\
\hline & & & $\mathbf{U}^{\mathbf{a}}$ \\
\hline & & No $U$ & Added \\
\hline Pt, 12 & Ir, 10 & 58.8 & 102.4 \\
\hline Pt, 12 & $R h, 10$ & 55.9 & 100.2 \\
\hline Ir, 10 & Pt, 12 & 169.6 & 99.4 \\
\hline Ir, 10 & $\mathrm{Rh}, 10$ & 94.9 & 100.3 \\
\hline Rh, 10 & Pt, 12 & 93.1 & 100.0 \\
\hline $\mathbf{R h}, \mathbf{1 0}$ & Ir, 10 & 85.0 & 99.6 \\
\hline
\end{tabular}

$240 \mathrm{mg} \mathrm{U} / \mathrm{ml}$.

results. In each case the uranium, present in hundredfold excess over the other elements, provided enough enhancement to eliminate the effect of equal concentra. tion of the other noble element. There is a limit to the amount of interference that uranium can overcome. As will be seen in Table IV, $1 \mathrm{~g}$ of uranium did not completely cancel the effect of $10 \mathrm{mg}$ of platinum on the absorbance of $0.1 \mathrm{mg}$ of iridium.

TABLE IV

\section{RECOVERY AND PRECISION OF DETERMINATION OF PLATINUM METALS IN URANIUM}

\begin{tabular}{|c|c|c|c|c|c|}
\hline \multirow{2}{*}{$\begin{array}{l}\text { Taken } \\
\text { (\%) }\end{array}$} & \multicolumn{3}{|c|}{ Impurities $\left(\mathscr{q}^{2}\right)$} & \multirow{2}{*}{$\begin{array}{c}\text { Found, Av. } \\
\text { (\% rel.) }\end{array}$} & \multirow{2}{*}{$\begin{array}{c}\text { Std. Dev. } \\
\text { (\% rel.) }\end{array}$} \\
\hline & $\mathbf{P t}$ & Ir & $\mathbf{R h}$ & & \\
\hline Pt, 0.01 & & 0.1 & 1.0 & 99.6 & 1.6 \\
\hline 0.1 & & 1.0 & 0.01 & 100.8 & 0.1 \\
\hline 1.0 & & 0.01 & 0.1 & 100.6 & 0.3 \\
\hline Ir, 0.01 & 1.0 & & 0.1 & 90.1 & 6.6 \\
\hline 0.1 & 0.01 & & 1.0 & 100.2 & 0.8 \\
\hline 1.0 & 0.1 & & 0.01 & 98.8 & 0.9 \\
\hline $\mathbf{R h}, \mathbf{0 . 0 1}$ & 0.1 & 1.0 & & 107.3 & 1.3 \\
\hline 0.1 & 1.0 & 0.01 & & 99.5 & 0.4 \\
\hline 1.0 & 0.01 & 0.1 & & 100.1 & 0.4 \\
\hline
\end{tabular}


Uranium contributes a slight backgrouid at the working wavelengths of all three elements. The blank, prepared and used as directed in the proceclure, corrects for this effect.

\section{Linearity of Response}

Linearity of the relationship between concentration and absorbance is desirable in any spectrophotometric method because it prevents the need for very close matching of calibration and sample solution concentrations. To investigate this characteristic for the elements in this study, we prepared each in concentrations of $0.25,0.50$, 0.75 , and $1.00 \mathrm{mg}$ in $25 \mathrm{ml}$, and added $40 \mathrm{mg} / \mathrm{ml}$ of uranium to each. We measured the absorbances by the recommended procedure, and corrected for the absorbance of a solution containing only uranium in a similar concentration. The averages of four measurements at each concentration are plotted in Fig. 1. The deviations from the line seem to be random errors, rather than curvature of the calibration line. Because the response is linear, the recommended procedure requires only one calibration solution, chosen to be near the expected concentration.

Our experience with our instrument is that the linearity is better if the instrument sensitivity is manipulated to give an absorbance reading less than $\mathbf{0 . 4 0 0}$.

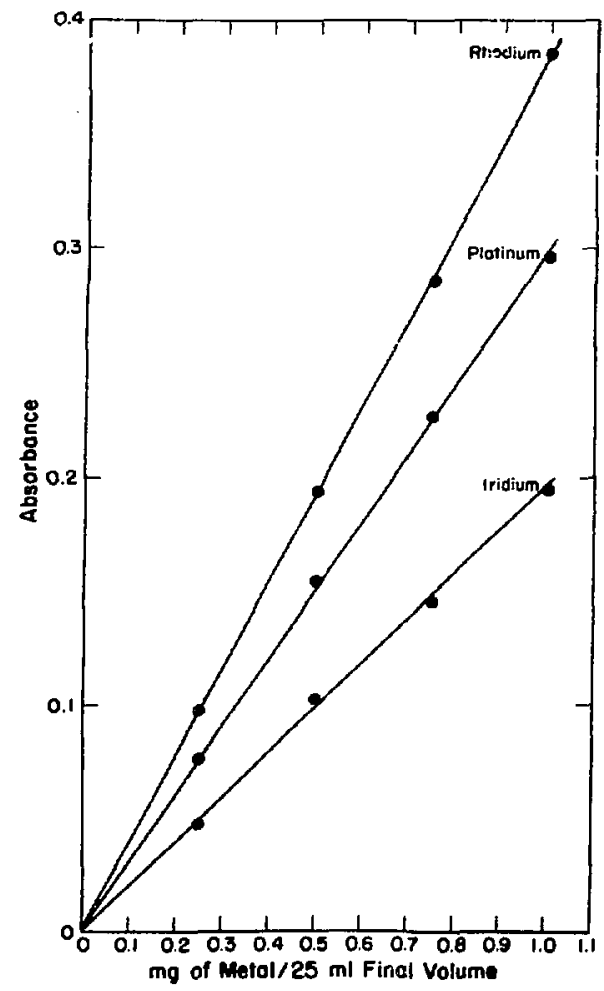

Fig. 1.

\section{RELIABIEITY}

We prepared three solutions, each containing $1 \mathrm{~g}$ of uranium per $25 \mathrm{ml}$ of solution as in the recommended procedure. To one solution we added $0.01 \%$ platinum, $0.1 \%$ iridium, and $1.0 \%$ rhodium compared to the uranium. The second solution contained $0.01 \%$ iridium, $0.1 \%$ rhodium, and $1.0 \%$ platinum. The third contained $0.01 \%$ rhodium, $0.1 \%$ platinum, and $1.0 \%$ iridium. Each was analyzed six times for each element, each time using for a reference a solution containing only the element sought and uranium. The results are shown in Table IV. The results indicate not only the precision that can be expected at the various concentration levels, but also where significant bias can be expected because of the presence of other platinum metals. We found more than $2 \%$ relative bias only where another metal was present in hundredfold excess over the element being sought. We recommend that any element present in hundredfold excess over the element being determined be added to the calibration selution.

\section{ACKNOWLEDGMENT}

We thank G. R. Waterbury for his helpful suggestions in this work.

\section{REFERENCES}

1. R. Lockyer and G. E. Hames, "The Quantitative Determination of Some Noble Metals by Atomic Absorption Spectroscopy," Analyst 84, 385-387 (1959).

2. J. M. Scarborough, "The Determinatior: by Atomic Absorption of Molybdenum, Ruthenium, Palladium, and Rhodium in Uranium Alloys," Anal. Chem. 41, 250-254 (1969).

3. B. Montford and S. C. Cribbs, "The Determination of Ruthenium by Atomic Absorption Spectrophotometry," Anal. Chem. Acta. 53, 101-108 (1971).

4. R. C. Mallett, D. C. G. Pearton, E. J. Ring, and T. W. Steele, "Interferences and Their Elimination in the Determination of the Noble Metals by Atomic Absorption Spectrophotometry," Talanta 19, 181-195 (1972).

5. E. Wichers, W. G. Schlect, and C. L. Gordon, "Attack of Refractory Platiniferous Materials by Acid Mixtures at Elevated Temperatures," J. Research, Nat'l Bur. Stds. 33, 363-381, 451-456, and 457-470 (1944).

6. C. F. Metz and G. R Waterbury, "Sealed-Tube Dissolution Method with Applications to Plutonium-Containing Materials," Los Alamos Scientific Laboratory report LA-3554 (July 1966). 